\title{
Developing, Implementing, and Evaluating Professional Development Initiatives for Graduate Teaching Assistants Facilitating Course-based Undergraduate Research Experiences (CUREs)
}

\author{
Amie Kern ${ }^{1}$, David Esparza, Amy Kulesza, Corrie Pieterson, Seema Rivera, \\ and Jeffrey T. Olimpo
}

${ }^{1}$ University of Texas at El Paso, Department of Biological Sciences, 500 W. University Ave, B226 Biology Bldg, El Paso TX 79968 USA

(amkern@miners.utep.edu; de245@cornell.edu)

\begin{abstract}
Within the last decade, course-based undergraduate research experiences (CUREs) have emerged as a viable mechanism to engage students in authentic scientific opportunities. While numerous studies have focused on student outcomes (e.g., science process skills development) in CURE learning environments, few studies have examined instructor preparation and pedagogy in such contexts. This is especially true for graduate teaching assistants (GTAs), who are frequently tasked with facilitating CUREs, yet who often receive little, if any, professional development (PD) to improve teaching skills that are vital to this type of instruction. In this workshop, we will address this need by engaging attendees in the following activities: (i) a brief introduction to existent GTA PD literature and programs, including sharing outcomes from our own research on CURE GTA PD; (ii) small- and large-group dialogue designed to identify core elements of CURE GTA PD; and (iii) development of a CURE GTA PD blueprint outlining one initiative that faculty can implement on their own campuses (with feedback provided from other participants via a gallery walk).
\end{abstract}

Keywords: Graduate Teaching Assistants, CURE, GTA, PD

\section{Mission, Review Process \& Disclaimer}

The Association for Biology Laboratory Education (ABLE) was founded in 1979 to promote information exchange among university and college educators actively concerned with teaching biology in a laboratory setting. The focus of ABLE is to improve the undergraduate biology laboratory experience by promoting the development and dissemination of interesting, innovative, and reliable laboratory exercises. For more information about ABLE, please visit http://www.ableweb.org/.

Advances in Biology Laboratory Education is the peer-reviewed publication of the conference of the Association for Biology Laboratory Education. Published articles and extended abstracts are evaluated and selected by a committee prior to presentation at the conference, peer-reviewed by participants at the conference, and edited by members of the ABLE Editorial Board. Published abstracts are evaluated and selected by a committee prior to presentation at the conference.

\section{Citing This Article}

Kern A, Esparza D, Kulesza A, Pieterson C, Rivera S, Olimpo JT. 2020. Developing, implementing, and evaluating professional development initiatives for graduate teaching assistants facilitating course-based undergraduate research experiences (CUREs). Article 39 In: McMahon K, editor. Advances in biology laboratory education. Volume 41. Publication of the 41st Conference of the Association for Biology Laboratory Education(ABLE). https://doi.org/10.37590/able.v41.abs39 
Compilation (C) 2020 by the Association for Biology Laboratory Education, ISBN 1-890444-17-0. All rights reserved. No part of this publication may be reproduced, stored in a retrieval system, or transmitted, in any form or by any means, electronic, mechanical, photocopying, recording, or otherwise, without the prior written permission of the copyright owner.

ABLE strongly encourages individuals to use the exercises in this volume in their teaching program. If this exercise is used solely at one's own institution with no intent for profit, it is excluded from the preceding copyright restriction, unless otherwise noted on the copyright notice of the individual chapter in this volume. Proper credit to this publication must be included in your laboratory outline for each use; a sample citation is given above. 